\title{
Stability Indicating HPTLC Method for Estimation of Modafinil in the Bulk and Tablet Formulation
}

\author{
Gaurang P. Pandya, Dr. Hitendra S. Joshi* \\ Department of Chemistry, Saurashtra University, Rajkot-360 005, Gujarat, India.
}

\begin{abstract}
A simple, selective, precise and stability-indicating high-performance thin layer chromatographic method for analysis of Modafinil, both as the bulk drug and in a tablet formulation has been developed and validated. Aluminum foil TLC plates precoated with silica gel 60F 254 were used as stationary phase ethyl acetate, acetone and methanol in the volume ratio of $(7: 2: 1 \mathrm{v} / \mathrm{v})$ respectively as mobile phase. A compact band $\left(\begin{array}{ll}R_{f} & 0.42 \pm 0.02\end{array}\right)$ was obtained for modafinil. Densitometric analysis was performed in absorbance mode at 232 $n m$. Linear regression analysis revealed a good linear relationship $\left(r^{2}=0.9995\right)$ between peak area and concentration in the range of 80-320 $\mathrm{ng} /$ spot. The method was validated for precision, recovery, and robustness. The limits of detection and quantitation were 15 and $50 \mathrm{ng} /$ spot, respectively. Modafinil was subjected to acid and alkaline hydrolysis, oxidation, photochemical and thermal degradation and underwent degradation under all these conditions. Statistical analysis proved the method enables repeatable, selective, and accurate analysis of the drug. It can be used for identification and quantitative analysis of Modafinil in the bulk drug and in tablet formulations.
\end{abstract}

Key Words: Modafinil HPTLC Validation Stability-indicating Degradation

\section{Introduction}

Modafinil is chemically 2-[(diphenylmethyl)sulfinyl] acetamide having molecular formula $\mathrm{C}_{15} \mathrm{H}_{15} \mathrm{NO}_{2} \mathrm{~S}$ and molecular mass $273.35 \mathrm{gm} / \mathrm{mol}$ (Figure 1). Modafinil is an analeptic drug manufactured by Cephalon, and is approved by the U.S. Food and Drug Administration (FDA) for the treatment of narcolepsy, shift work sleep disorder and excessive daytime sleepiness associated with obstructive sleep apnea. Narcolepsy is caused by dysfunction of a family of wakefulness-promoting and sleep-suppressing peptides, the orexins. Orexin neurons are activated by modafinil. Modafinil also affects tuberomammillary nucleus [1-2].<smiles>NC(=O)CS(=O)C(c1ccccc1)c1ccccc1</smiles>

Figure-1 Structure of Modafinil

However extensive research into the interaction of modafinil with a large number of neurotransmitter systems has been done, an exact mechanism or set of mechanisms of action remains uncertain. It seems that modafinil, like other stimulants, increases the release of monoamines [3-4], specifically the catecholamine4, norepinephrine [5-6] and dopamine from the synaptic terminals. Though, modafinil also elevates hypothalamic histamine levels, leading some researchers to consider Modafinil a "wakefulness promoting agent" rather than a classic amphetamine-like stimulant [7-8]. Even though modafinil's histaminergic action, it still partially shares the actions of amphetamine-class stimulants due to its effects on norepinephrine and dopamine [9-11].

Modafinil has been prohibited by World Anti Doping Agency since 2004 so that there are so many bio analytical methods are reported to detect Modafinil in urine and blood plasma by GC-MS[12], LC-MS/MS[1214],UPLC-MS[15-17] and HPLC[22]. Some methods are also reported for chiral resolution of modafinil enantiomers by HPLC [18-21]. Besides bioanalytical methods few methods are reported to determine Modafinil in tablet dosage form by HPLC [23-25]. Furthermore these methods are not impressionable to achieve the high throughput study which can be possible by optimizing the method in such a way which includes cost effectiveness with optimum selectivity. Hence, it can be maximum utilize for the analysis of formulation development and stability testing as well as at quality control laboratory for routine use.

In recent times, there is an increase tendency towards the development of stability-indicating assay, using the approach of stress testing as mentioned in the ICH guidelines (Q1A). It is also recommended to carry 
out stress testing on the drug substance to establish its inherent stability characteristics and to hold up the suitability of the proposed analytical method. In this study our approach is to study degradation behavior of Modafinil and development of a validated stability indicating HPTLC assay method.

\subsection{Chemicals and reagents}

\section{Experimental}

The modafinil working standard was provided as a gift sample by Alembic pharmaceutical Ltd, Baroda. All chemicals and reagents used were of AR grade. The formulation, $100 \mathrm{mg}$ and $200 \mathrm{mg}$ is available in market by brand name PROVIGIL.

\subsection{HPTLC Instrumentation and conditions}

Chromatography was performed on Merck TLC plates pre-coated with silica gel 60 F254 $(10 \mathrm{~cm} \times 10$ $\mathrm{cm}$ with $250 \mu \mathrm{m}$ layer thicknesses) from E. Merck, Germany. Before use the plates were prewashed with methanol then dried in the current of dry air and activated at $110{ }^{\circ} \mathrm{C}$ for $5 \mathrm{~min}$. The samples were applied onto the plates as a band with $4 \mathrm{~mm}$ width using Camag $100 \mu \mathrm{l}$ sample syringe (Hamilton, Switzerland) with a Linomat 5 applicator (Camag, Switzerland). The mobile phase consisted of ethyl acetate-acetone-methanol $(7: 2: 1 \mathrm{v} / \mathrm{v} / \mathrm{v})$. Linear ascending development was carried out in a twin trough glass chamber (for $10 \times 10 \mathrm{~cm}$ ) previously saturated with mobile phase vapour for $30 \mathrm{~min}$ at room temperature and relative humidity $60 \pm 5 \%$. The development distance was approximately $80 \mathrm{~mm}$. After development the plates were dried in current of air by use of an air dryer. Densitometric scanning, at $232 \mathrm{~nm}$, was performed with a Camag TLC scanner III, operated by Wincats Software (V 1.4.2, Camag) in absorbance mode. The selection of wavelength was based on maximum absorbance for optimum sensitivity. The source of radiation was a deuterium lamp emitting a continuous UV spectrum in the range 190-400 $\mathrm{nm}$. The slit dimensions were $5 \mathrm{~mm} \times 0.45 \mathrm{~mm}$.

\subsection{Preparation of standard solution}

The standard modafinil $10 \mathrm{mg}$ was weighed accurately and transferred to volumetric flask $100 \mathrm{ml}$. It was dissolved and sonicated for few minutes and diluted up to the mark with methanol to obtain final concentration of $100 \mu \mathrm{g} / \mathrm{ml}$ and the resulting solution was used as working standard stock solution.

\subsection{Preparation of sample solution}

To determine the content of modafinil in tablets formulations, 20 branded tablets were weighed; their mean weight was calculated and crushed to fine powder. Tablet powder equivalent to 1 tablet of modafinil was weighed and transferred to $100 \mathrm{ml}$ volumetric flask then dissolved with methanol and further diluted with methanol. It was kept for ultrasonication for few min; the solution was then filtered through Whatmann filter paper No. 41 and further dilution was made with methanol to get the final sample solution of $100 \mu \mathrm{g} / \mathrm{ml}$. The resultant solution was used as such for analysis.

\subsection{Method validation}

The method was validated in compliance with ICH guidelines. The following parameters were performed and evaluated for the validation of developed method.

\subsubsection{Linearity}

Appropriate volume of aliquots from standard modafinil stock solutions were prepared and applied on the TLC plate covering the range from 200-800 ng/spot with the help of micro liter syringe using an automatic sample applicator. The plates were developed, dried and scanned densitometrically at $232 \mathrm{~nm}$. Each concentration was applied seven times to the plate and the plate was developed as described above. Peak areas were plotted against corresponding concentrations to furnish the calibration plot

Table 1

Regression analysis of calibration curve

\begin{tabular}{|c|c|}
\hline Parameters & Result \\
\hline Linearity Range(ng/Band) & $200-800$ \\
\hline correlation coefficient & 0.998 \\
\hline Slope & 82.46 \\
\hline Intercept & 120.2 \\
\hline
\end{tabular}




\subsubsection{Accuracy}

To check the recovery of the drug at different levels in formulations, samples were analysed at 3 different level 50,100, and 150\% of modafinil standard by proposed method and the recovered amount of drugs were calculated. The experiment was conducted in triplicate.

Table 2

Result of recovery studies

\begin{tabular}{|c|c|c|c|c|c|}
\hline Sr. no. & $\begin{array}{c}\text { Level of } \\
\text { Recovery }\end{array}$ & $\begin{array}{c}\text { Amount of } \\
\text { drug } \\
\text { taken(mg) }\end{array}$ & $\begin{array}{c}\text { Amount of } \\
\text { drug found(mg) }\end{array}$ & $\begin{array}{c}\% \\
\text { Recovery }\end{array}$ & \% RSD \\
\hline 1 & 50 & 50 & 50.11 & 100.22 & 1.859 \\
\hline 2 & 100 & 100 & 100.31 & 100.31 & 1.797 \\
\hline 3 & 150 & 150 & 149.97 & 99.38 & 1.491 \\
\hline
\end{tabular}

a) Mean of three determinations

\subsubsection{Precision}

Precision of the developed method was measured by repeatability, intra-day and inter-day precision. In repeatability study analyses of six replicates of same concentration (500 ng) were done by developed method. For intra-day and inter-day precision, three sample sets of tablet sample and standard were analyzed in triplicate by developed method on the same day and on three different days, respectively.

\subsubsection{Robustness}

Small changes in the chromatographic conditions were introduced and the effects on the results were examined. Slight changes in the composition of mobile phase $( \pm 0.1 \mathrm{ml})$ were made in the used optimized mobile phase. The time from spotting to chromatography and time from chromatography to scan was varied at \pm 5 minutes. The chromatographic development distance was varied in the range of $\pm 5 \mathrm{~mm}$. The effects of these changes on both $\mathrm{R}_{\mathrm{F}}$ value and peak area were assessed by calculating relative standard deviation (\%RSD).

Table 3

Result of robustness studies

\begin{tabular}{|c|c|}
\hline Condition & $\begin{array}{c}\text { RSD } \\
(\%)\end{array}$ \\
\hline mobile phase composition & 1.34 \\
\hline amount of mobile phase & 0.95 \\
\hline chamber saturation time & 1.21 \\
\hline time from application to chromatography & 1.58 \\
\hline time from chromatography to scanning & 0.66 \\
\hline Distance from application to solvent front & 0.83 \\
\hline
\end{tabular}

\subsubsection{Limits of Detection and Quantification}

To determine the limits of detection (LOD) and limit of quantification (LOQ), different dilution of standard solution of drug were applied along with methanol as the blank. The LOD and LOQ were determined on the basis of signal to noise ratio until the average responses of triplicate analysis were obtained approximately 3 and 10 times the responses of the blank respectively.

\subsubsection{Specificity}

The specificity of the method was determined by analysis of drug standards and samples. The band for modafinil in the sample was identified by comparing the $R_{\mathrm{f}}$ value and spectrum of the band with those of the band from a standard. The peak purity of modafinil was assessed by comparing spectra acquired at three different positions on the peak, i.e. the peak start (S), peak apex (M), and peak end (E) positions of the peak.

\subsection{Analysis of Marketed Formulation}

Assay of marketed tablet was done through developed HPTLC method. The sample solution was made as depicted in section 2.4. Same volume $(5 \mu \mathrm{L})$ of Standard solution and sample solution were applied on TLC. The experiment was carried out for six sample solutions. The chromatogram obtained is shown in Figure 2. 
Table 4

Summary of validation parameters

\begin{tabular}{|c|c|c|}
\hline Parameter & Result & $\%$ RSD \\
\hline$\lambda(\mathrm{nm})$ & 232 & \\
\hline $\mathrm{R}_{\mathrm{F}}$ & 0.42 & \\
\hline Linear Range (ng/Band) & $200-800$ & \\
\hline Accuracy(at 100\% level) & 100.31 & 1.797 \\
\hline Precision & & \\
\hline Intraday precision & 99.98 & 1.579 \\
\hline interday precision & 99.57 & 0.983 \\
\hline Limit Of Detection (ng/Band) & 15 & \\
\hline Limit Of Quantitation (ng/Band) & 50 & \\
\hline
\end{tabular}

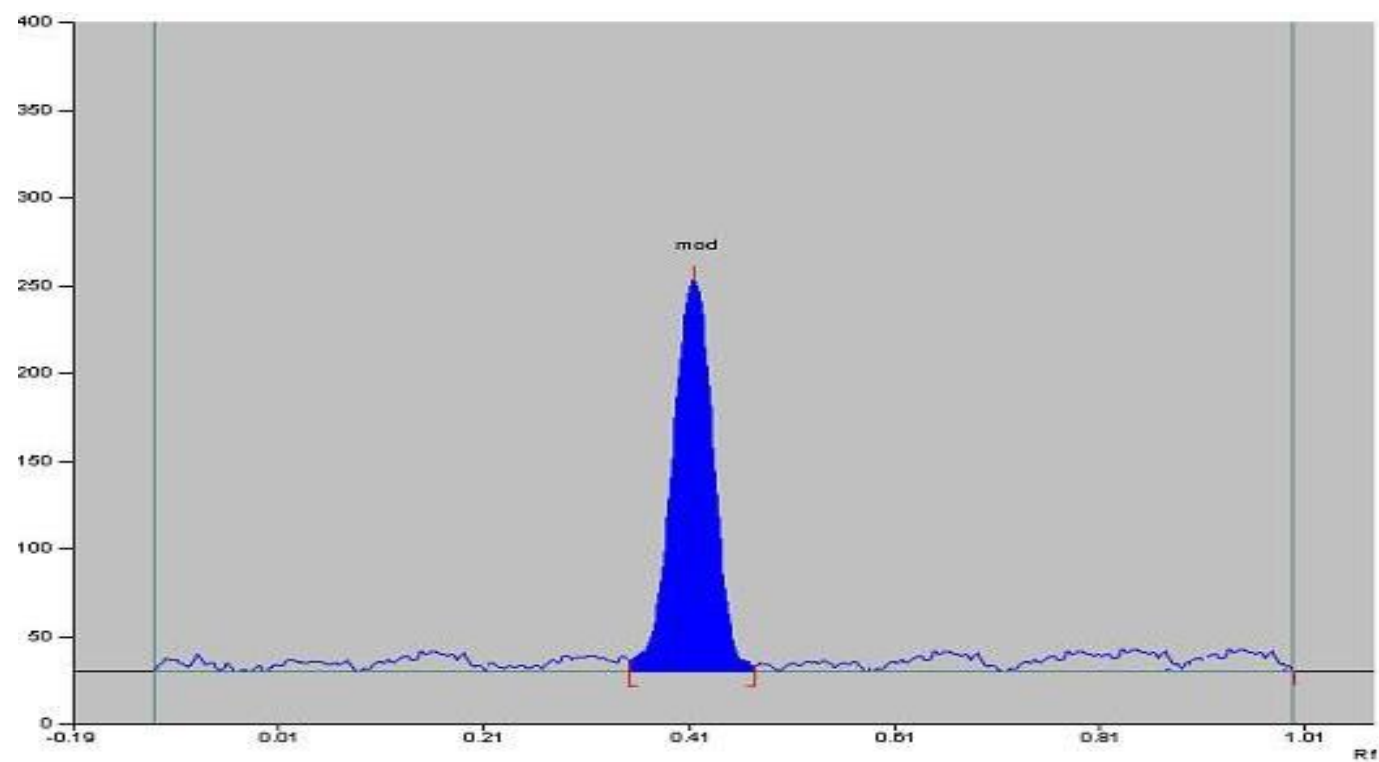

Figure-2 Chromatogram of Modafinil drug sample

Table 5

Analysis of tablet formulation

\begin{tabular}{|c|c|c|c|c|c|}
\hline Method & Drug & $\begin{array}{c}\text { Lable claim } \\
{[\mathrm{mg} / \text { tablet }]}\end{array}$ & $\begin{array}{c}\text { Amount found } \\
{[\mathrm{mg} / \text { tablet }]^{\mathrm{a})}}\end{array}$ & $\begin{array}{c}\text { Drug Assay } \\
{[\%]^{\mathrm{a}}}\end{array}$ & $\%$ RSD \\
\hline $\begin{array}{c}\text { TLC- } \\
\text { Densitometry }\end{array}$ & Modafinil & 100 & 99.84 & 99.84 & 0.786 \\
\hline
\end{tabular}

a) Mean of six determinations

\subsection{Forced Degradation studies}

A stock solution containing $10 \mathrm{mg}$ modafinil in $10 \mathrm{ml}$ methanol was prepared. This solution was used for forced degradation to provide an indication of the stability indicating property and specificity of the method. In all degradation studies the average peak area of modafinil after application $(500 \mathrm{ng} / \mathrm{spot})$ of seven replicates was obtained after development and scanning of the plate as described above.

\subsubsection{Acid and Base Degradation}

Modafinil $(10 \mathrm{mg}$ ) was separately dissolved in $10 \mathrm{ml}$ of methanolic solution of $0.2 \mathrm{~N} \mathrm{HCl}$ and $0.5 \mathrm{~N}$ $\mathrm{NaOH}$. These solutions were refluxed at $80^{\circ} \mathrm{C}$ for $2 \mathrm{~h}$ in the dark in order to exclude the possible degradative effect of light. $1 \mathrm{ml}$ of treated solution were taken and neutralized and then diluted up to $10 \mathrm{ml}$ with methanol. Then this diluted sample was used to apply on TLC plate in triplicate $(500 \mathrm{ng} / \mathrm{spot})$. The plates were chromatographed and analysed by proposed method. 


\subsubsection{Oxidative Degradation}

Modafinil (10 mg) was dissolved in $10 \mathrm{ml}$ of methanolic solution of hydrogen peroxide $(30 \%, v / v)$ and the mixture was kept for $48 \mathrm{~h}$ at room temperature in the dark, to exclude the possible degradative effect of light. The solutions $(1 \mathrm{ml})$ were diluted to $10 \mathrm{ml}$ with methanol and further proceed as described for acid and base degradation.

\subsubsection{Dry Heat Degradation}

Dry heat studies were performed by keeping powdered drug in oven $\left(60^{\circ} \mathrm{C}\right)$ for $6 \mathrm{hrs}$. Samples were withdrawn, dissolved in methanol, diluted suitably and appropriate volumes of resultant solution were applied on TLC plate and densitograms were developed.

\subsubsection{Photo Degradation}

Photo degradation studies were carried out by keeping modafinil drug sample in sunlight for 4 days. Sample solution was taken and diluted in methanol, and appropriate volume of the resultant solution were applied and chromatographed as described above.

\subsection{Development of the optimum mobile phase}

\section{Results And Discussion}

TLC procedure was optimized with a view to develop a stability-indicating assay method. The drug reference standards were spotted on the TLC plates and developed in different solvent systems. Different mobile phases were tried to resolve modafinil and degradation products. Best suited mobile phase was found to ethyl acetate, acetone and methanol in the volume ratio of $(7: 2: 1 \mathrm{v} / \mathrm{v})$ respectively. Developed mobile phase enabled good resolution, and a sharp and symmetrical peak of $R_{F} 0.42$ for modafinil (Fig. 2) form a compact and nondiffused band. It was observed that prewashing of TLC plates with methanol (followed by drying and activation) and pre-saturation of TLC chamber with mobile phase for $30 \mathrm{~min}$ (the optimum saturation time) ensured good reproducibility and peak shape.

\subsection{Validation of the developed stability-indicating method}

The response for the drug was found to be linear in the concentration range 200-800 ng/band for modafinil. The results of regression analysis are depicted in Table 1. The accuracy of the method was determined at 50, 100 and 150\% level. Results of accuracy study are expressed in terms of \% recovery (Table 2). According to results of robustness studies shown in Table 3. $\%$ RSD value does not exceed more than 2 . So the developed method is robust. The \%RSD value for precision study was found to be not more than $2 \%$ for modafinil, thus confirming precision of the method. The Limit of Detection and Limit of Quantitation were found to be $15 \mathrm{ng} / \mathrm{band}$ and $50 \mathrm{ng} / \mathrm{band}$ respectively for analyte. The results are shown in Table 4. The specificity of the method was ascertained by peak purity profiling studies. In analysis of marketed formulation the mean assay result was found to be $99.84 \%$ (Table 5). From the result obtained we can conclude that there is no interference of the excipients present in the formulation. The low \%RSD suggests the suitability of developed method for routine analysis.

\subsection{Degradation observed}

After applying different stress conditions upon modafinil, following results were observed by analyzing samples using the developed method. About 21.50\% drug was degraded (Figure 3) under oxidative condition and major degradation peaks were observed at $0.18,0.20$ and $0.23 \mathrm{R}_{\mathrm{F}}$ values. In acid hydrolysis modafinil was degraded (Figure 4) about $17.35 \%$ and degraded product was observed at 0.14 and $0.19 \mathrm{R}_{\mathrm{F}}$ value, however in alkali hydrolysis some harsh condition was required compared to that in acid degradation. Initially, $0.1 \mathrm{~N} \mathrm{NaOH}$ was used and refluxed at $80^{\circ} \mathrm{C}$ for 2 hours, yet no degradation was observed; then strength of alkali was increased to $0.5 \mathrm{~N}$ and refluxed at $80^{\circ} \mathrm{C}$ for 2 hours resulting in $8.20 \%$ degradation (Figure 5) and degradation peaks were observed at $0.23,0.27$ and $0.32 \mathrm{R}_{\mathrm{F}}$ values. Under dry heat (Oven, $80 \mathrm{0C}, 6 \mathrm{hr}$ ), drug was found to be degraded up to $9.25 \%$ with decrease in area only, whereas under Photolytic studies, no additional peaks were observed and drug peak area remained constant. This indicates stability of modafinil in UV light. In all forced degradation condition the drug peak was well resolved from degradation products. 


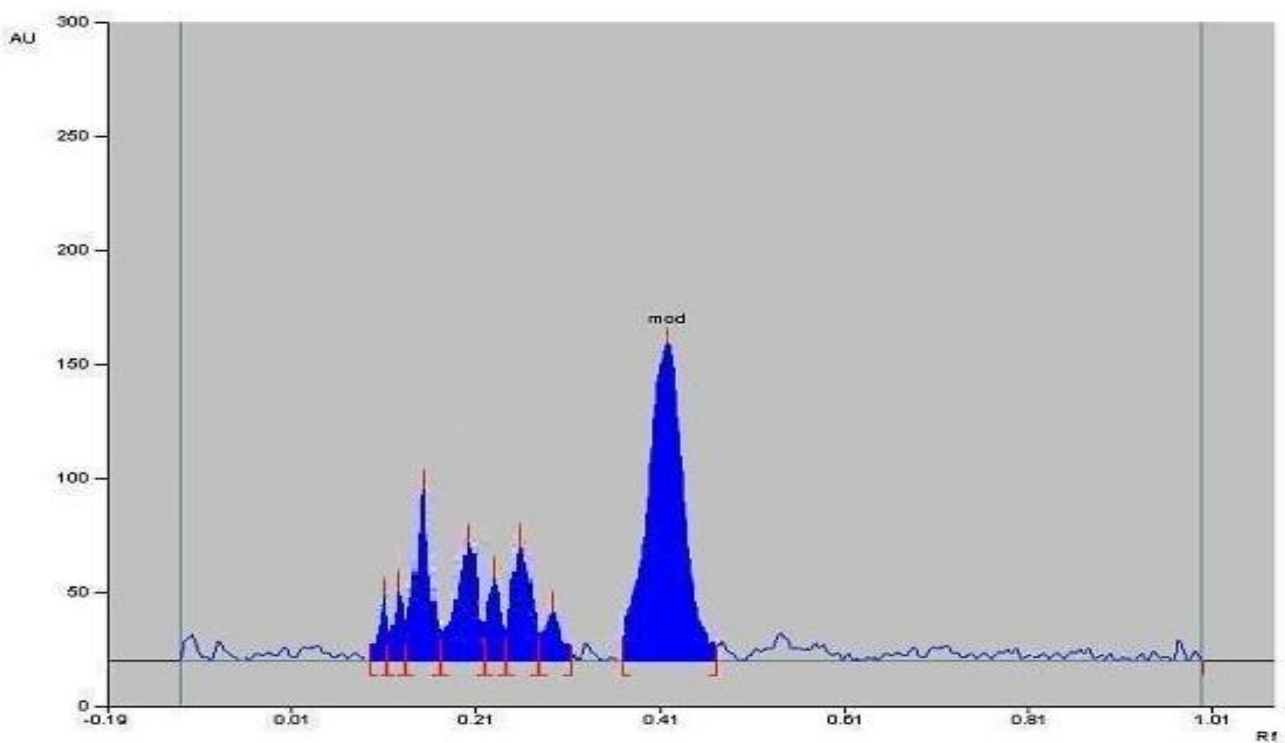

Figure-3 Chromatogram of Modafinil after Oxidative degradation

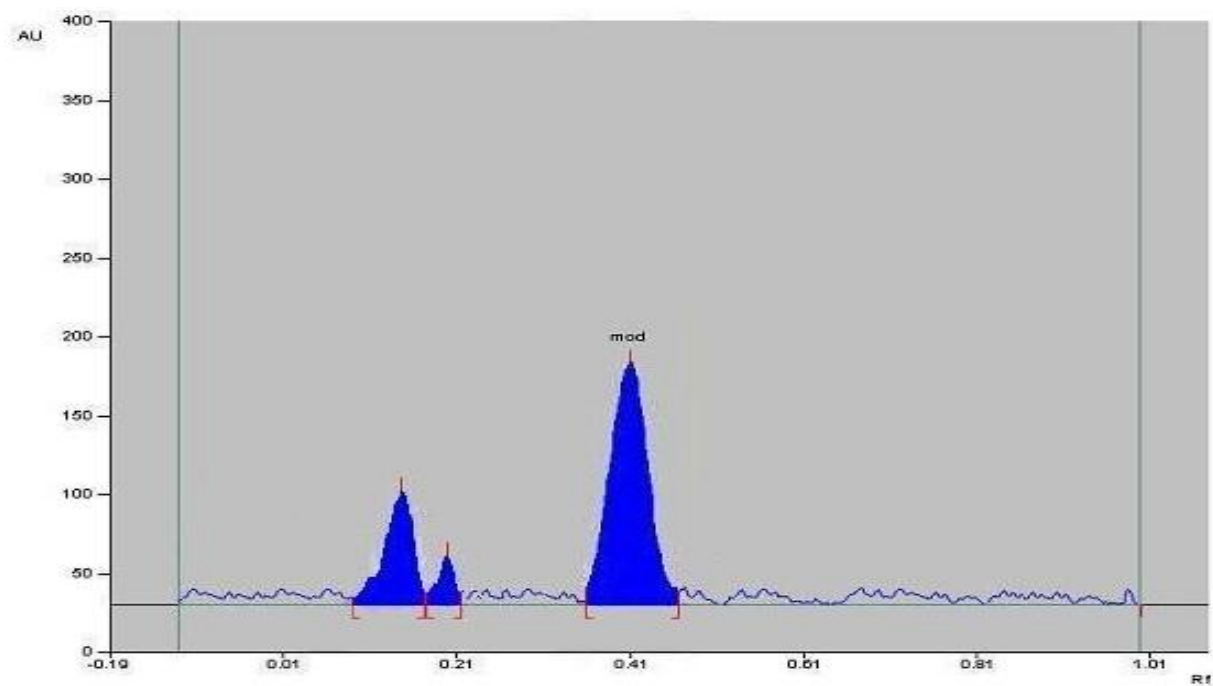

Figure-4 Chromatogram of Modafinil after Acid degradation

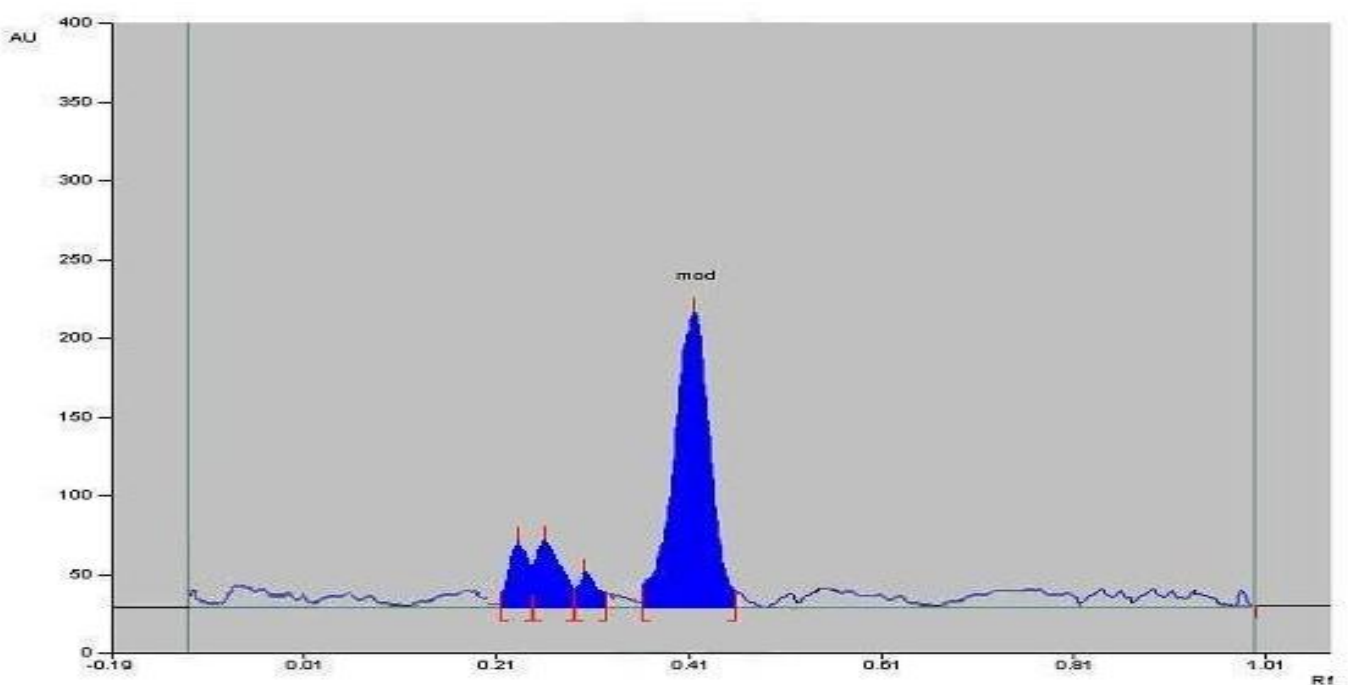

Figure-5 Chromatogram of Modafinil after Alkali degradation 


\section{Conclusion}

Based on the above study and result, it can be concluded that the developed HPTLC method is simple, precise, accurate, rapid, selective and sensitive for the determination of modafinil in tablet formulation as well as in bulk drugs. The products formed after forced decomposition studies were resolved from the bulk drug response. From the peak purity profile studies, it was confirmed that the peak of the degradation product was not interfering with the peak of drugs. It confirms that peak for degradation product of drug can be resolved from the drug peak by this method; hence it can be used as stability indicating method. The method can minimize the time and cost of analysis. It has also utilized the merit of applying several samples on TLC plates which can be advantageous for regulatory quality control laboratories. The method does not require expensive chemical and solvents, thus it can stand for a good alternative for already existing hplc methods. It is proposed for routine analysis of these drugs in presence of degradation products in stability study.

\section{Acknowledgements}

The authors are thankful for facilities \& grants given under UGC- Special Assistance Programme (SAP),Department Research Support (DRS), Department of Science \& Technology (DST) New Delhi, Fund For Improvement of Science \& Technology (FIST), National Facility for Drug Discovery (NFDD) and Department of Chemistry, Saurashtra University, Rajkot - 360005 (INDIA) for providing analytical facilities.

\section{References}

[1] R. Chemelli, J. Willie, C. Sinton, J. Elmquist, T. Scammell, C. Lee, J. Richardson, S. Williams, Y. Xiong, Y. Kisanuki et al, Cell (Cambridge, Massachusetts) 98 (1999) 437-451.

[2] T. Scammell, I. Estabrooke, M. McCarthy, R. Chemelli, M. Yanagisawa, M. Miller, C. Saper, Journal of Neurosci. 20 (2000) 86208628.

[3] D. Zara, M. Orosco, C. Rouch, B. Gerard, S. Nicolaidis, NeuroReport, 12 (2001) 3533-3537.

[4] J. Duteil, F. Rambert, J. Pessonnier, J. Hermant, R. Gombert, E. Assous, Euro. J. Pharmaco. 180 (1990) $49-58$.

[5] B. Madras, Z. Xie, Z. Lin, A. Jassen, H. Panas, L. Lynch, R. Johnson, E. Livni, T. Spencer, A. Bonab, et al Journal of Pharmaco. Experi. Therap. 319 (2006) 561-569.

[6] M. Minzenberg, A. Watrous, J. Yoon, S. Ursu, C. Carter, Science (Washington, DC, U.S.), 322 (2008) 1700-1702.

[7] J. Lin, B. Roussel, H. Akaoka, P. Fort, G. Debilly, M. Jouvet, Brain Res. 591 (1992) 319-26.

[8] J. Lin, Y. Dauvilliers, I. Arnulf, H. Bastuji, C. Anaclet, R. Parmentier, L. Kocher, M. Yanagisawa, P. Lehert, X. Ligneau et al, Neurobio. Disease 30 (2008) 74-83.

[9] T. Ishizuka, Y. Sakamoto, T. Sakurai, A. Yamatodani, Neurosci. Letters. 339 (2003) 143-146.

[10] T. Ishizuka, Y. Sakamoto, T. Sakurai, A. Yamatodani, Euro. J. Pharmaco. 578 (2008) 209-215.

[11] R. Parmentier, C. Anaclet, C. Guhennec, E. Brousseau, D. Bricout, T. Giboulot, D. Bozyczko-Coyne, K. Spiegel, H. Ohtsu, M. Williams et al, Biochem. Pharmaco. 73 (2007) 1157-1171.

[12] S. Dubey, S. Ahi, I. Reddy, T., Kaur, A. Beotra, S. Jain, Ind. J. Pharmaco. 41 (2009) 278-283.

[13] M. Mazzarino, X. Torre, F. Botre, Anal. Bioanal. Chem. 392 (2008) 681-698.

[14] M. Mazzarino, F. Botre, Rapid Com. Mass Spectr. 20 (2006) 3465-3476.

[15] G. Jimenez, K. Deventer, K. Roels, E. Van, Anal. Chim. Acta 721 (2012) 137-146.

[16] E. Deconinck, K. Verlinde, P. Courselle, J. De Beer, J. Pharm. Biomed. Anal. 59 (2012) 38-43.

[17] H. Thoerngren, F. Oestervall, M. Garle J. Mass Spectr. 43 (2008) 980-992.

[18] T. Lourenco, D. Armstrong, Q. Cass, Chromatographia 71 (2010) 361-372.

[19] Y. Ji, X., Fan, X. Zhu, Zhongguo Yiyao Gongye Zazhi 34 (2010) 251-256.

[20] R. Rao, D. Shinde, Biomed. Chrom. 23 (2009) 811-816.

[21] J. Donovan, R. Malcolm, J. Markowitz, C. DeVane, Therap. Drug Monit. 25 (2003) 197-202.

[22] H. Schwertnera, S. Kong, J. Pharm. and Biomed. Anal. 37 (2005) 475-479.

[23] X. Li, M. Jin, J. Yi, Zhongguo Yaofang 18 (2007) 1729-1730.

[24] C. Li, H. Lu, Guangdong Yaoxueyuan Xuebao, 18 (2002) 90-92.

[25] Н. Ma, T. Guo, M. Yan, Zhongguo Yiyao Gongye Zazhi, 40 (2009) 377-378. 